\title{
La representación de la Guerra de 1941 en diario El Comercio
}

\section{The representation of the War of 1941 in El Comercio newspaper}

DOI: https://doi.org/10.29166/tyc.v1i21.2476

\section{Katerinne Orquera Polanco}

Candidata doctoral en Historia Latinoamericana por la Universidad Andina Simón Bolívar, Sede Ecuador. Obtuvo la beca 2018 del Instituto Francés de Estudios Latinoamericanos (IFEA) para la investigación "La prensa: sus condiciones materiales y sus intelectuales. El diario El Comercio de Quito, 1935-1945". Intereses de investigación: historia de la prensa y el espacio público en el siglo XX y la historia de las mujeres en el Estado republicano.

Correo: katerinne.orquera@gmail.com

\section{Resumen}

En 1941 el Ecuador mantuvo un conflicto bélico con el Perú que incluyó la invasión tanto de territorios amazónicos como de poblaciones que no se hallaban en disputa. El resultado de la guerra modificó no solo el mapa territorial del país sino también el horizonte de expectativa de sus habitantes. El presente artículo examina la forma en que esos hechos se representaron en los editoriales de diario El Comercio de Quito, realizados al calor de los acontecimientos, y el modo en que sus editores los relacionaron con la II Guerra Mundial, contexto en el cual tuvo que resolverse el conflicto bélico local.

Palabras clave: El Comercio, representación, Guerra Ecuador-Perú, 1941, II Guerra Mundial.

\section{Abstract}

In 1941, Ecuador maintained a war conflict with Peru that included the invasion of both, Amazonian territories and populations which were not in dispute. The result of the war modified not only the territorial map of the country but also the horizon of expectation of its inhabitants. This article examines the way in which these events were represented in the editorials of the newspaper El Comercio de Quito, carried out in the heat of the events, and the way in which their editors related them to World War II, a context in which the local war conflict had to be resolved.

Keywords: El Comercio, representation, Ecuador-Perú war, 1941, World War II. 


\section{Introducción}

El editorial de un diario constituye su posición oficial respecto de la coyuntura inmediata en la que circula y lo posiciona en el espacio público. Esta opinión, que se genera al tiempo que los hechos están acaeciendo, es un relato que busca dar sentido y orden a la realidad para el consumo de los lectores. De esa manera, las prácticas sociales se articulan con la forma en que son percibidas -mediante palabras, gestos y ritos- al tiempo que esas percepciones dan sentido a la existencia de los individuos, en marcos sociales regulatorios que son el resultado de representaciones enfrentadas del mundo (Chartier, 1987, p. 14).

El propósito de este artículo es mirar la articulación de los hechos sucedidos en el Ecuador durante 1941, marcados por el enfrentamiento bélico con el Perú, con la posición editorial de diario $E l$ Comercio de Quito durante ese año, en el marco internacional de la II Guerra Mundial. Esto permite dar cuenta de la forma en que los editores del impreso entendieron y representaron la realidad que vivía la nación, en tanto comunidad de sentido que los periódicos ayudaban a imaginar (Anderson, 1993, pp. 46-47).

La investigación se guía por el concepto de "representación", desarrollado por Roger Chartier, en la línea de la historia cultural, que relaciona los hechos con las percepciones de los mismos, en consideración de que los dos - hechos y percepciones-son parte de la realidad de la experiencia humana, que articula la construcción discursiva del mundo social con la construcción social de los discursos. Dicha relación se puede rastrear en los impresos porque, como objetos, mues- tran las condiciones objetivas que hicieron posible la enunciación de la realidad $\mathrm{y}$, como discursos, dan cuenta de la forma en que sus enunciados modelaron la realidad (Chartier, 1996, p. 8).

El análisis se realiza mediante la revisión de los editoriales de El Comercio de 1941 y se divide en tres acápites que se refieren a los hechos recogidos en los editoriales del diario y la forma en que los representó con el propósito de darle sentido a lo que estaba sucediendo; el uso de historia como un arma de defensa del territorio en disputa; y la apelación al Panamericanismo como el ámbito internacional donde se debía reivindicar la posición nacional, en el contexto de la II Guerra Mundial.

\section{Los hechos de 1941 y su representación el diario El Comercio}

$\mathrm{Al}$ iniciar la década de los cuarenta del siglo XX, en Quito circulaban tres diarios con regularidad: El Día, El Debate y El Comercio. Los dos primeros eran más de opinión que informativos, mientras que el tercero era un diario noticioso que concentraba en su cuarta página el editorial oficial y la opinión de sus redactores, lógica que había iniciado en 1935, cuando la segunda administración del impreso, dirigida por Carlos Mantilla Jácome, emprendió un plan de modernización que, entre otras cosas, amplió el tiraje de 6 mil a 30 mil ejemplares diarios, con lo cual logró pasar de diario local a nacional. (Fernández, 1956, p. 155).

Asimismo, El Comercio había dividido las actividades de sus productores culturales entre generadores de opinión (llamados redactores por el diario) y creadores de noticias (definidos como cronis- 
tas, reporteros o corresponsales, de acuerdo a sus funciones específicas). Los redactores de mayor confianza del editor tenían a cargo escribir el editorial oficial del impreso ("Cuerpo principal de redactores de 'El Comercio' y 'Últimas Noticias"”. 1 de enero de 1941. El Comercio, p. 3; "Personal de la Empresa 'El Comercio"”. 1 de enero de 1941. El Comercio, p. 6; Salvador Lara, 2009, p. 15).

A inicios de 1941, Europa estaba en armas por y en contra de los totalitarismos, pero el conflicto aún no había llegado a los territorios de América. De acuerdo con Eric Hobsbawm, la invasión de Rusia y la declaración de guerra a los Estados Unidos (hechos sucedidos entre mediados y fines de 1941) determinaron el resultado de la II Guerra Mundial, pero las potencias del Eje solo perdieron iniciativa militar hacia 1943 (Hobsbawm, 1997, p. 49). Es decir, que en 1941 el mundo aún no veía la posibilidad del fin de una guerra que -de acuerdo al tono de las publicaciones de El Comercio- se sentía como una amenaza a la propia vida, aunque estuviera sucediendo al otro lado del Atlántico.

La situación del país no era mejor que la del resto del mundo. Desde los años veinte, el Ecuador registraba una profunda crisis en todos los órdenes sociales. Entre otras cosas, las exportaciones, que habían llegado a 20 millones de dólares constantes en 1920, no volvieron a registrar ese nivel hasta 1943; la inflación duplicó el precio de las subsistencias, sobre todo en la década de 1940; y los conflictos sociales urbanos y rurales se expresaron en manifestaciones de muchedumbres interclasistas que dieron como resultado la formación de los primeros sindicatos obreros (Maiguashca \& North, 1991, pp. 95-98; Bustos, 2011, pp. 175-176).
De acuerdo con Silvia Vega Ugalde, a inicios de los cuarenta las relaciones de producción del país todavía eran semicapitalistas, pues la mayor cantidad de la fuerza de trabajo no se retribuía con salarios. En el ámbito político, el país era gobernado por los liberales, aunque con la colaboración de conservadores como Julio Tobar Donoso, que ocupó el ministerio de Relaciones Exteriores en dos gobiernos, incluido el de Carlos Alberto Arroyo del Río que estaba en el poder al suceder la invasión peruana (Vega Ugalde, 2014, pp. 45, 54).

Las condiciones sociales descritas empeoraron con la invasión del territorio y el enfrentamiento bélico con el Perú, que inició en los primeros días del año, pero tomó un giro distinto al producirse el ataque de Japón a los Estados Unidos, el 7 de diciembre de 1941, que determinó la entrada directa de ese país en la II Guerra Mundial y el alineamiento del continente a favor de los Aliados, temas que marcaron la agenda editorial de diario El Comercio, como lo muestra el Cuadro 1.

Como se puede notar, los límites con el Perú y la II Guerra Mundial sumaron el $54.51 \%$ de la producción editorial del año, es decir que el diario consideraba como el mayor problema social del Ecuador la amenaza de la vida por parte de enemigos externos. En cuanto a la política interna, El Comercio se ocupó sobre todo de las facultades extraordinarias otorgadas al presidente de la República luego de un acto cívico que terminó de forma violenta; la solicitud del impreso era entregar el tema al Ministerio de Gobierno y trabajar en materias trascendentes: "lo internacional, lo hacendatario, las cuestiones agrícolas, las industriales, las obras públicas y los problemas sociales y educa- 
Cuadro 1. Editoriales de El Comercio - 1941

\begin{tabular}{|l|c|c|}
\hline \multicolumn{1}{|c|}{ Temas } & No.de editoriales & $\%$ \\
\hline $\begin{array}{l}\text { Guerra con el Perú (Excursiones del ejército peruano en la frontera. } \\
\text { Ocupación del territorio. Derechos históricos del Ecuador sobre la Amazonía) }\end{array}$ & 151 & 41,36 \\
\hline Política nacional (Gobierno. Congreso. Partidos políticos. Elecciones) & 82 & 22,46 \\
\hline II Guerra Mundial / Panamericanismo & 48 & 13,15 \\
\hline Estado (Administración. Educación. Infraestructura. Salud pública. Burocracia) & 44 & 12,02 \\
\hline Economía (Presupuesto. Importación-exportación. Sectores económicos) & 36 & 9,86 \\
\hline Rol de la prensa & 2 & 0,54 \\
\hline Migración & 1 & 0,27 \\
\hline Ambiente & 1 & 0,27 \\
\hline TOTAL & 365 & 100,00 \\
\hline
\end{tabular}

Elaboración propia.

Fuente: Editoriales de diario El Comercio de 1941, Archivo Biblioteca Aurelio Espinosa Pólit (ABAEP).

tivos." ("Intermitencia en la acción". 20 de enero de 1941. El Comercio, p. 4).

También en la administración del Estado y en el ámbito económico el diario representaba un país en desorden, de lo cual responsabilizaba tanto al gobierno como a la oposición, mientras que los sectores populares eran vistos como masas arrastradas por líderes inescrupulosos. Por ejemplo, aseguraba que el Partido Socialista mantenía un punto de vista irracional, cuando que se necesitaba "buena voluntad" para evitar gobiernos dictatoriales ("Las elecciones y las extraordinarias". 2 de marzo de 1941. El Comercio, p. 4).

La suma de los acontecimientos, marcados por la ineficacia en la protección del territorio, las conspiraciones de unos contra otros y la situación económica y social, se evidenciaba en el editorial de cierre del año, donde el sentimiento de derrota era evidente:
Ecuador recordará con honda amargura su historia en este año [...] El nuestro fue ese pueblo confiado que ni supo alegrarse ni atinó a defenderse: creíamos que la justicia era suficiente protección para nuestros derechos y malgastamos todas las energías en discusiones inútiles que se convirtieron en zarabandas políticas despreciables. "La nación ante el tiempo". 31 de diciembre de 1941. El Comercio, p. 4)

El diario concluía que todos los sectores debían contribuir a limpiar la afrenta, para lo cual proponía comenzar por vivir organizadamente, cosa que consideraba como el mayor patriotismo posible. Pero antes de terminar el año, $E l$ Comercio había hecho algunas propuestas para reivindicar los derechos nacionales del territorio en disputa y argumentar ante el continente su legítima tenencia, tema que es objeto de análisis del siguiente apartado. 


\section{Los derechos históricos, el arma de defensa ante el Perú}

Como se ha visto en el cuadro presentado anteriormente, la frontera con el Perú fue la mayor preocupación de $\mathrm{ElCO}$ mercio en 1941. Solo en marzo no se hicieron referencias al tema. En enero y abril se registraron nueve y cinco editoriales, respectivamente; en mayo, septiembre y noviembre hay apenas un artículo, pero no desaparece; y, como es de esperar, los meses con mayor número de artículos corresponden a los del conflicto armado: julio y agosto, cuando prácticamente no se hablaba de otra cosa, pues en el primer caso hubo 27 editoriales y en el segundo $25^{1}$.

Los artículos de opinión sobre el conflicto en la frontera inician casi al mismo tiempo que el año, pues para el 5 de enero ya se publicaba el primero. $E l$ Comercio aseguraba que el Perú había violado la ética de los procedimientos al volver al Oriente objeto de su codicia. Para conseguir su objetivo, decía, se aprovechaba de la bastedad del territorio y de los conflictos internos del Ecuador, burlando la fe internacional ("Un examen de posiciones". 5 de enero de 1941. El Comercio, p. 4).

Los titulares reflejaban un sentido de reivindicación nacional, que se constata en el uso de las palabras como Ecuador (ecuatoriano, ecuatorianidad), que constan en doce titulares, Patria (patrió- tico, patriotismo) están en diez, nación (nacionalidad) en siete y civismo (cívicas) en siete más. Todo lo cual suma 36 titulares que apelaban a la defensa de la nación, 10\% de la producción de opinión del diario en el año.

Las acciones del Perú eran representadas como un afán expansionista y atribuidas a la mala fe del país vecino que buscaba aprovechar el momento de conflicto mundial a su favor, con una política similar a la que mantenía el Eje, mientras que el Ecuador defendía su disposición de arreglar el tema limítrofe por una vía pacífica ("Fe en la justicia y el derecho". 3 de enero de 1941. El Comercio, p. 4). Esta interpretación de la realidad coincide con la que sostenían el Estado y la Academia Nacional de Historia, respecto a los derechos históricos del Ecuador sobre los territorios amazónicos, por lo determinado en las Cédulas Reales, base de la división territorial de los países de América Latina ${ }^{2}$.

Si bien en la representación de $E l$ Comercio se figuraba al Perú cercano al Eje, Hernán Ibarra explica que era una percepción errada, pues desde que Manuel Prado había asumido la Presidencia (1939) se estableció una alianza con los Estados Unidos, fundada en razones económicas (Ibarra, 1999, p. 35). Este planteamiento es corroborado por la investigación de Vega, quien asegura que la confrontación militar entre los dos países fue fraguada por empresas petroleras norteamericanas que buscaban detener

1 Una cronología de los hechos militares de la Guerra del 41 se puede encontrar en el libro Larrea Alba, Luis. (1988). Geopolítica. Aplicación a la estrategia militar. Quito: CCE.

2 Estas representaciones pueden verse en los diversos editoriales de El Comercio de 1941. Sobre el imaginario respecto al territorio nacional véase Ibarra, Hernán. (1999). Diálogos. La guerra de 1941 entre Ecuador y Perú. Una reinterpretación. Quito: Caap; y la posición de la Academia de Historia es explicada en Bustos, Guillermo. (2011). La urdimbre de la Historia Patria. Escritura de la historia, rituales de la memoria y nacionalismo en Ecuador (1870-1950). (Tesis doctoral). University of Michigan, Ann Arbor. 
las concesiones otorgadas por el Ecuador a capitales ingleses desde 1937 (Vega Ugalde, 2014, p. 59).

Es posible suponer que El Comercio vinculó la invasión peruana a las acciones del Eje en Europa porque tenía una línea editorial favorable al liderazgo de Estados Unidos en el continente, la cual justificaba desde su adscripción a los principios liberales y a la democracia, que le llevaba a afirmar: "el proceso del mundo en lo posterior debía resolverse a cuesta del triunfo de Occidente; en definición histórica, con la victoria preliminar del sentido de la democracia norteamericana." (Fernández, 1956, p. 157).

Sin embargo, si se consideran los informes de Edgar K. Thompson, agente especial del FBI en el país, la nación a la que Estados Unidos podía considerar como la de mayor actividad nazi era el Ecuador, pues el Ejército se encontraba bajo el control de la Misión Militar Italiana y la policía era subvertida por el banquero Víctor Emilio Estrada, a quien consideraban abiertamente pronazi y parte de su equipo de propaganda, financiada tanto por el partido nacionalsocialista alemán como por comerciantes de ese país radicados en el Ecuador y por el propio Estrada (Becker, 2016, pp. 158-159).

En esta línea de ideas resulta llamativo que El Comercio no hiciera ninguna referencia al rol de las Fuerzas Armadas en el conflicto. Los editoriales del diario hablaban de la potencia militar durante la etapa de la Independencia, consideradas como el pasado heroico que debía impulsar a la nación ("El 27 de febrero". 27 de febrero de 1941. El Comercio, p. 4). Quizá esta ausencia de referencias se deba a que el Ejército de aquel entonces no era tanto un cuerpo profesional cuanto un árbitro de la pugna liberal-conservadora, es decir, era un actor político que podía censurar al diario (Vega Ugalde, 2014, p. 69).

Durante 1941 El Comercio publicó diez editoriales donde la historia era el argumento de defensa del territorio y, prácticamente saltando un mes, se hablaba una o dos veces de la historia nacional y, sobre todo, de Quito como legítima dueña del territorio oriental, dado que desde esta ciudad salieron los "descubridores" europeos del río Amazonas, con indígenas que sacrificaron su vida en dicha empresa. Estos editoriales pueden atribuirse a su jefe de Redacción, Isaac J. Barrera, quien era miembro activo de la Academia Nacional de Historia, al tiempo que ejercía el cargo de jefe de redacción del diario, cuyo diletantismo erudito era auxiliar al ejercicio del periodismo y cumplía una función pública de tipo patriótico muy apreciada en la época de referencia (Bustos, 2017, p. 237).

Sin embargo, las referencias históricas también parecen haber servido al diario para evitar hablar de las responsabilidades de las autoridades gubernamentales de ese momento, pues en medio del conflicto armado y de la ocupación peruana que ya había llegado hasta El Oro, el diario llamaba a los ciudadanos a defender la patria, pero evitaba hacer referencia a las responsabilidades de los gobernantes en la situación del país, como sí habían hecho otros diarios ("El deber heroico". 29 de noviembre de 1941. El Comercio, p. 4).

Justamente por estas diferencias, $E l$ Comercio se preguntó en dos editoriales sobre el papel de la prensa y llamó a sus colegas a intervenir honrada y honrosamente, como la caballería de los tiempos 
modernos, que mediante la palabra podía sancionar y propagar el conocimiento útil ("Deberes del periodismo". 28 de junio de 1941. El Comercio, p. 4). De esa manera, buscó posicionarse como el portador de una opinión siempre equilibrada y se diferenciaba de los otros dos diarios de la ciudad, que sí habían evidenciado la inacción y los errores del gobierno.

El Día denunció la falta de acción oportuna del régimen, en base a documentación oficial enviada por Víctor Naranjo, cónsul ecuatoriano en Paita y anteriormente redactor de ese diario, quien desde diciembre de 1940 había informado de la movilización del Ejército peruano en la frontera, lo que provocó que el director y varios de sus redactores fueran perseguidos por el Estado (Albuja Galindo, 2013, t. 2, p. 102; Norris, 2005, t. I, p. 270).

Mientras que El Debate, siempre crítico con el gobierno, fue clausurado en 1942 por publicar la carta abierta de Leonidas Plaza Lasso, capitán del Ejército, quien cuestionó al Presidente por los múltiples errores cometidos durante el enfrentamiento armado (Plaza Lasso, L. 27 de mayo de 1942. "Carta abierta del Cptn. Leonidas Plaza Lasso al Ministro de Gobierno”. El Debate, primera página). La clausura de este impreso fue parte de las represalias que el Ejecutivo tomó contra los militares jóvenes que actuaron en la frontera y que resquebrajó la unidad institucional del Ejército (Vega Ugalde, 2014, p. 67).

El peso real de la prensa en el conflicto armado y sus consecuencias se evidencia en dos hechos: por una parte, la afirmación del canciller Julio Tobar Donoso respecto a que "no fue la Cancillería la que inició la 'ofensiva' contra el Perú, sino el Ecuador entero, movido por al- gunos escritores que apenas si caían en cuenta de sus responsabilidades" (Tobar Donoso, 1982, pp. 101-102). Y por la otra, su representación en la Junta Consultiva del 20 de enero de 1942 que, conjuntamente con el Presidente, los Ministros de Estado y el Jefe del Estado Mayor General, autorizó la negociación del arreglo definitivo en Río de Janeiro, producto de lo cual se firmó el protocolo de límites con el Perú (Larrea Alba, 1988, pp. 212-213).

También los informes diplomáticos chilenos dan cuenta de la activa participación de los periódicos en el conflicto, que incluso habrían informado de una supuesta intención del Perú de agredir la frontera con Chile, afirmación que no pudo ser confirmada (Tapia Figueroa, 2008, p. 73). De todas maneras, las líneas editoriales de los diarios difirieron unas de otras, mostrándose $\mathrm{El} \mathrm{Co}$ mercio como el menos cuestionador respecto al gobierno, lo que puede explicarse por una línea editorial liberal que hacía temer un ascenso de los conservadores al poder, como ha señalado Ospina respecto al Ejército (Ospina, inédito, pp. 2-3); y también la relación de amistad que Arroyo del Río mantenía con el jefe de Redacción, Isaac J. Barrera, la cual es posible suponer que se extendía también a su editor (Barrera B. \& Barrera B., 1981, p. 197).

$\mathrm{El}$ argumento que había sostenido El Comercio de los derechos históricos del Ecuador sobre los territorios amazónicos, mantenido también por la Academia Nacional de Historia y la Cancillería ecuatoriana debía exponerse en el ámbito del Panamericanismo, considerado por el diario como el más propicio para defender los intereses del Ecuador, como se expone en el siguiente acápite. 


\section{El Panamericanismo como espacio de defensa}

La política internacional ocupó los espacios editoriales de 1941, excepto en agosto que se concentró en el conflicto armado en el territorio nacional, dada la intensificación de los ataques peruanos contra poblaciones de El Oro a partir del 22 de julio (Larrea Alba, 1988, pp. 191193). El resto del año el promedio fue de cuatro editoriales por mes, excepto en diciembre, cuando llegó a diez por el ataque de Japón a Pearl Harbor y el pánico que produjo en el continente.

La palabra América se encuentra en 43 titulares, lo que muestra la importancia que en ese momento se le daba a la unión continental, considerada indispensable para afrontar la amenaza de la II Guerra Mundial. El Comercio esperaba que el Panamericanismo trajera seguridad, ayudara a resolver los problemas interamericanos y a reactivar la economía. En ese contexto, el diario representaba a Estados Unidos como un hermano mayor que podía brindar protección y ejemplo al Ecuador:

Este es momento en que nos encontramos y en el que toca a la poderosa economía de los Estados Unidos de Norteamérica impulsar esta empresa de unificación y de progreso. No van a beneficiarse las naciones que exploten sus riquezas; van a contribuir con ellas al bienestar continental. Los Estados Unidos extenderán sus industrias con la ayuda de material llevado de los otros territorios del continente; de tal manera que el desenvolvimiento del trabajo sea fructífero en su totalidad [...] pero es preciso también caer en la cuenta de que nos encontramos en situación que no admite las dilatorias acostumbradas por idiosincrasia racial o por dejadez congénita. ("La hora de la actividad". 17 de febrero de 1941. El Comercio, p. 4)
La favorable actitud de El Comercio hacia los principios representados por los Estados Unidos estaba en relación directa con el desprestigio de Europa después de dos guerras mundiales. Sus editores consideraban a América la tierra del porvenir para la civilización, pues el viejo continente no era más el referente de la razón sino una región de la cual protegerse. Es así que el impreso consideraba a las "Conferencias Panamericanas como concretaciones [sic] de una necesidad vuelta conciencia." ("En Río de Janeiro”. 13 de marzo de 1941. El Comercio, p. 4).

La influencia de Estados Unidos se acrecentó con su ingreso directo en la II Guerra Mundial, cosa que también afectó al Ecuador por la cercanía al Canal de Panamá. Esto se evidencia en el cambio de posición del diario respecto a la posible ocupación de las Galápagos. Mientras en febrero criticaba la propuesta de "un periodista yanqui" sobre un posible "intercambio" de las islas por apoyo norteamericano en el conflicto limítrofe y conminaba al gobierno estadounidense a no intervenir en los asuntos nacionales ("Alarma en América". 16 de febrero de 1941. El Comercio. p. 4), en diciembre, luego del ataque japonés a Pearl Harbor, el diario consideró que la entrega de Baltra a tropas estadounidenses era el aporte nacional a la civilización. ("En América y por América”. 13 de diciembre de 1941. El Comercio, p. 4)

De todas maneras, El Comercio unía las dos guerras a un mismo destino de solución: el Panamericanismo. En diciembre de 1941 llamaba a Estados Unidos a no esperar que existiera unión, cooperación y defensa total si no se arreglaba la situación del Ecuador. Para demostrar su argumento, usaba la 
metáfora de una poderosa maquinaria a la que le faltaba un "insignificante tornillo", capaz de resentir la estructura total. Esa "pieza que no funciona, que falta en el gran mecanismo americano", decía su editorial, era la cuestión fronteriza y la ocupación arbitraria de territorios por parte de las tropas peruanas ("La buena voluntad". 25 de diciembre de 1941. El Comercio, p. 4).

Con este llamado a actuar en el conflicto entre el Ecuador y Perú desde el ámbito del Panamericanismo liderado por los Estados Unidos concluían las referencias editoriales de El Comercio de 1941 respecto a las dos guerras que se vivían en ese momento y su posible solución. Pero el conflicto armado no terminó con ese año, sino que se mantuvo durante un mes más, hasta la suscripción del "Protocolo de paz, amistad y límites entre el Ecuador y el Perú" (29 de enero de 1942), firmado durante la Conferencia de Río de Janeiro, convocada para expresar el respaldo a los Estados Unidos en su ingreso directo a la II Guerra Mundial y buscar el alineamiento de los países del continente a la estrategia de los Aliados.

En esa Conferencia, donde $\mathrm{El} \mathrm{Co-}$ mercio había colocado las expectativas de poder expresar las razones nacionales respecto a los derechos territoriales, no solo se impidió al canciller ecuatoriano tomar la palabra sino que los delegados diplomáticos nacionales recibieron una reconvención del canciller brasileño Oswaldo Aranha respecto a la forma en que debían presentarse ante la comunidad internacional: "organícense, sean país" fue, de acuerdo con Tobar Donoso "la amonestación, casi fatigosa, de aquel Estadista" (Tobar Donoso, en Borja, 1978, p. 252).

Si bien la declaración del canciller Tobar Donoso podría considerarse una justificación ante la situación vivida en Río de Janeiro, los informes diplomáticos chilenos también indican que la resolución final del conflicto tuvo más que ver con la situación interna del Ecuador -un gobierno débil y unas Fuerzas Armadas sin preparación para enfrentar a la maquinaria bélica peruana- que con cualquier otra circunstancia (Tapia Figueroa, 2008, p. 55.)

Pero, como ya se mencionó antes, la percepción de desorden no era solo externa, también en los editoriales publicados por El Comercio se insistía en la necesidad de la organización social. El diario proponía una especie de Estado ideal, donde gobernantes y gobernados conocieran y cumplieran sus obligaciones. Por ejemplo, en cuanto a la "cuestión social”, tan sobresaliente en aquellos años, el diario llamaba al Estado a responder a su deber de proteger a la comunidad y advertía que la organización era el principio necesario para mayor eficacia de los resultados ("Servicios de asistencia”. 23 de enero de 1941. El Comercio, p. 4).

En todos los editoriales del año, aun cuando El Comercio evitaba criticar al gobierno, representaba una anomia social que no podía estar demasiado lejana de la realidad, pues de ello dependía que pudiera ganar capital simbólico como un instrumento del avance colectivo que, mediante la publicación de ideas escritas, buscaba "culturizar al público lector, tratando de instruir encauzando al país por el camino del progreso y del bienestar colectivo", de acuerdo con la declaración de principios realizada en 1940 ("El Director. No somos políticos ni politiqueros". 7 de enero de 1940. El Comercio, primera página). 


\section{Conclusiones}

La categoría representación ha ayudado a mostrar tanto la relación como la distancia entre los hechos y sus representaciones en diario El Comercio de Quito durante el año 1941, marcado no solo en lo noticioso sino también en lo editorial por el conflicto armado mantenido con el Perú. En esa representación, lo más relevante resulta la percepción de inseguridad de los redactores del diario encargados de escribir los editoriales, tanto por la guerra en la propia frontera como por el conflicto mundial que alimentaban una sensación de incertidumbre entre los intelectuales que actuaban en su Jefatura de Redacción.

La respuesta de estos escritores a la falta de certezas, especialmente por el conflicto en la propia frontera, fue buscar respuestas para sí y para su comunidad de lectores mediante la apelación de un pasado considerado glorioso que legitimaba las reivindicaciones de posesión de los territorios orientales, es decir, busca- ron aportar a la defensa de la nación en guerra mediante las que eran sus únicas armas: las ideas y su exposición ante la opinión pública, cosa que debía replicarse en el escenario internacional para obtener el triunfo de la razón, representada por sus propias argumentaciones, según creían.

El ámbito propicio para que estas argumentaciones fueran recogidas, entendidas y procesadas era el Panamericanismo, forma de organización internacional liderada por los Estados Unidos, constituidos como guía de la civilización occidental, de acuerdo con la representación realizada por el diario, donde el Ecuador podía ingresar si se constituía en un país ordenado, expectativa que chocó con la realidad de una comunidad internacional poco interesada en escuchar los argumentos nacionales, en momentos que la alineación con los Aliados era el objetivo mayor bajo el que quedó subsumido el conflicto territorial que enfrentaba el Ecuador y sus argumentos sobre los derechos históricos en la Amazonia. 


\section{Bibliografía}

Albuja Galindo, Alfredo. (2013). El periodismo en la dialéctica política ecuatoriana. Tomo 2. Quito: La Tierra.

Anderson, Benedict. (1993 [1983]). Comunidades Imaginadas. Reflexiones sobre el origen y la difusión del nacionalismo.

Ciudad de México: Fondo de Cultura Económica.

Arroyo del Río, Carlos Alberto. (1999). Por la pendiente del sacrificio. Quito: Banco Central del Ecuador.

Barrera B., Inés \& Barrera B., Eulalia. (1981). Epistolario a Isaac J. Barrera (recolección póstuma). Quito: Casa de la Cultura Ecuatoriana.

Becker, Marc. "La Gloriosa bajo la mirada imperial del gobierno de los Estados Unidos". En Santiago Cabrera Hanna (Ed.). La Gloriosa, ¿revolución que no fue?(153-169). Quito: Universidad Andina Simón Bolívar, Sede Ecuador / Corporación Editora Nacional, 2016.

Borja, Rafael. (1978). El descalabro del 41. Quito: Casa de la Cultura Ecuatoriana

Bustos, Guillermo. (2011). La urdimbre de la Historia Patria. Escritura de la historia, rituales de la memoria y nacionalismo en Ecuador (1870-1950). Tesis doctoral. University of Michigan, Ann Arbor.

Bustos, Guillermo. (2017). El culto a la nación. Escritura de la historia y rituales de la memoria en Ecuador, 1870-1950.

Quito: Fondo de Cultura Económica / Universidad Andina Simón Bolívar, Sede Ecuador.

Chartier, Roger. (1987 [1984]). Sociedad y escritura en la Edad Moderna. Ciudad de México: Instituto Mora.

Chartier, Roger. (1996). Escribir las prácticas. Foucault, De Certeau, Marin. Buenos Aires: Manantial.

Chartier, Roger. (2006). ¿Qué es un libro? En Chartier, Roger. (Ed.). ¿Qué es un texto? (8-35). Madrid: ediciones Ciencias Sociales.

Fernández, Jorge. (1956). Tránsito a la libertad. Biografía de diario "El Comercio". Quito: El Comercio.

Hobsbawm, Eric. (1997 [1995]). Historia del siglo XX. Barcelona: Crítica.

Ibarra, Hernán. (1999). Diálogos. La guerra de 1941 entre Ecuador y Perú. Una reinterpretación. Quito: Caap.

Larrea Alba, Luis. (1988). Geopolítica. Aplicación a la estrategia militar. Quito: CCE.

Maiguashca, Juan \& North, Liisa. (1991). Orígenes y significados del velasquismo: lucha de clases y participación política en el Ecuador, 1920-1972. En La cuestión regional y el poder (89-159). Quito: FLACSO / CERLAC / Corporación Editora Nacional.

Norris, Robert. (2005). El gran ausente. Biografía de Velasco Ibarra. Tomo I. Quito: LibriMundi / Enrique Grosse Luemern. Ospina, Pablo. (Inédito). La aleación inestable. Origen y consolidación de un Estado transformista. Ecuador, 1920-1960. Quito, Universidad Andina Simón Bolívar, Sede Ecuador.

Palti, Elías José. (2003). Los diarios y el sistema político mexicano en tiempo de la República Restaurada (1867-1876). En Paula Alonso (Comp.). Construcciones impresas. Panfletos, diarios y revistas en la formación de los estados nacionales en América Latina, 1820-1920 (167-181). Buenos Aires: Fondo de Cultura Económica.

Salvador Lara, Jorge. (2009). Presentación. En Jorge Fernández y Marcelo Fernández, Medio siglo de pensamiento periodístico (13-28). Quito: Universidad Internacional del Ecuador.

Tapia Figueroa, Claudio Andrés. (2008). La negociación que no fue: diplomacia chilena en el conflicto entre Ecuador y Perú en el Amazonas 1941-1942. Viña del Mar: Centro de Estudios Latinoamericanos, CEL/ Instituto de Historia y Ciencias Sociales / Universidad de Valparaiso.

Tobar Donoso, Julio. (1982). La invasión peruana y el Protocolo de Río. Quito: Banco Central del Ecuador. 
Vega Ugalde, Silvia. (2014 [1987]). La Gloriosa. De la revolución del 28 de mayo de 1944 a la contrarevolución velasquista. Quito: La Tierra.

\section{Otras fuentes y archivos}

Archivo Biblioteca Aurelio Espinosa Pólit (ABAEP)

1941 Diario El Comercio de Quito. 